\title{
Traduire
}

Ine autre perspective sur I t raduction

Revue française de la traduction

$226 \mid 2012$

Face au miroir

\section{Quand un traducteur mène l'enquête au temps de Blanche de Castille}

\section{Marie-Agnès Schmitt}

\section{(2) OpenEdition}

1 Journals

Édition électronique

URL : http://journals.openedition.org/traduire/150

DOI : $10.4000 /$ traduire.150

ISSN : 2272-9992

Éditeur

Société française des traducteurs

Édition imprimée

Date de publication : 1 janvier 2012

Pagination : 72-73

ISBN : 039-773X

ISSN : 0395-773X

Référence électronique

Marie-Agnès Schmitt, "Quand un traducteur mène l'enquête au temps de Blanche de Castille »,

Traduire [En ligne], 226 | 2012, mis en ligne le 03 février 2014, consulté le 10 octobre 2020. URL : http:// journals.openedition.org/traduire/150; DOI : https://doi.org/10.4000/traduire.150 


\title{
Quand un traducteur mène l'enquête au temps de Blanche de Castille
}

\author{
Marie-Agnès Schmitt
}

1 Je voudrais partager avec vous mon coup de cœur pour Le troubadour du Châtelet, de Marie Visconti, paru aux éditions Calleva. Ne vous méprenez pas sur le titre, ce n'est pas un roman courtois, mais un excellent roman policier historique !

2 L'action débute à l'automne 1226 à Paris, et le Châtelet en question est une prison sinistre. Pendant que Louis VIII assiège Avignon, cité "hérétique ", des libelles attaquant la vertu de son épouse, la reine Blanche, sont répandus dans Paris, où elle réside. Pour étouffer dans l'œuf une crise politique de nature à discréditer le pouvoir royal et à le mettre à la merci des grands feudataires, les conseillers du roi demandent à Josseran de trouver l'auteur des libelles. En effet, la reine Blanche vient de Castille, où l'on parle espagnol mais aussi arabe. Or Josseran pratique la « langue sarrasine » pour avoir vécu longtemps en Orient.

3 C'est assez rare que, dans un roman policier, un enquêteur soit un traducteur pour mériter d'être signalé! Si ses qualités (esprit d'analyse, soif de comprendre, choix rapide entre plusieurs hypothèses) sont des atouts dans la résolution de l'enquête, son savoir l'expose à de grands risques. C'est qu'en 1226, autrement dit après la Quatrième croisade et au début de l'Inquisition, on ne plaisante pas: entre pratiquer la langue sarrasine (celle des ennemis de la chrétienté) et le bûcher, il n'y a pas loin !

\section{Un survol historique aide à comprendre}

4 Les traducteurs étaient principalement des orientalistes. En effet, pour les pays occidentaux, le latin était alors une langue vivante, celle de l'Église et des lettrés, et il servait de vecteur linguistique commun, contrairement au grec, autre langue classique, et à plus forte raison à l'hébreu et l'arabe. Or une découverte majeure a bouleversé au XIIe siècle le monde intellectuel. En Espagne, après la Reconquête, on a trouvé un trésor 
enfoui dans les bibliothèques des lettrés musulmans : les traités scientifiques des Grecs, traduits en arabe. Comme les originaux grecs avaient été perdus ou ne subsistaient qu'à l'état de fragments, les érudits orientalistes traduisirent ces textes arabes en latin, ce qui fit progresser considérablement la pensée occidentale. Ainsi la Castille devint un haut lieu culturel : les traducteurs (juifs, mozarabes et chrétiens) travaillaient dans un bel esprit de tolérance. Mais ailleurs on considérait avec méfiance ceux qui décryptaient ces "grimoires" impénétrables : par un raccourci simpliste ils étaient assimilés à des magiciens car ils savaient lire des alphabets et symboles que l'œil du profane jugeait être ceux utilisés par les sorciers !

5 Parallèlement, la phobie du «Sarrasin » explique l'hostilité envers la reine Blanche à Paris, où beaucoup traitent de haut «la Castillane ». À l'époque, c'était une injure, l'équivalent de "rustre ", parce que les nobles castillans de sa suite préféraient utiliser entre eux l'espagnol ou l'arabe, langues en usage en Espagne où gouvernait « le roi des trois religions ».

6 Josseran, qui a acquis en Orient un regard dénué de préjugés, respecte quant à lui la reine et se met à son service pour résoudre l'affaire des libelles. Rappelons que, loin d'être un exposé sur le métier de traducteur, ce roman est un roman policier. Aussi, après des libelles, ce sont des meurtres qui sont commis. S'y ajoute la disparition d'un étrange grimoire richement enluminé, le Livre Grégeois. Y a-t-il un lien entre ces affaires? Est-il d'ordre économique, financier et/ou politique? Grâce à ses connaissances linguistiques et culturelles, ainsi qu'à sa hardiesse (car cet érudit se double d'un homme d'action), Josseran saura jeter entre le monde occidental et le monde oriental le pont nécessaire pour faire la lumière et démêler le rôle réel de l'énigmatique « Troubadour du Châtelet ».

7 L'auteur a très bien su restituer l'esprit du Moyen-âge dans toute sa force brutale, avec ses interdits et ses préjugés, mais aussi avec ses havres de paix et ses lueurs d'espoir. Écrite dans un style enlevé, l'intrigue nous tient habilement en haleine jusqu'au dénouement.

8 De l'atmosphère feutrée du palais royal à l'ambiance colorée des rues de Paris, le Moyen-âge renaît avec bonheur et subtilité. Les personnages sont bien campés, on les dirait croqués sur le vif. Par exemple, Panfile, "marchand de l'eau» de son état (armateur, selon la terminologie actuelle), est truculent à souhait, et la jeune fille surnommée l'Herbulette apporte par ses étranges pouvoirs une touche de surnaturel. Nous côtoyons les bateliers de la Seine et les bateleurs qui jonglent sur les ponts. Nous assistons à l'ambassade d'un émir venu d'Al-Andalous rencontrer Blanche de Castille. Nous partageons les préoccupations des petites gens, des bourgeois et des aristocrates à travers ces détails qui font le sel de la vie quotidienne. Les murailles de Paris se dressent sous nos yeux, les rues bruissent d'une vie intense, les maisons recèlent des secrets enfouis au tréfonds des âmes que va emporter la Faucheuse. Et, en arrière-plan, nous parviennent les échos de cette guerre fratricide entre les barons du Nord et les « hérétiques » du Sud...

9 Vous l'aurez compris, je recommande chaudement Le troubadour du Châtelet, disponible notamment à l'adresse http://www.calleva.fr/Le-Troubadour-du-Chatelet, à toutes celles et à tous ceux qui souhaitent se plonger dans une palpitante lecture. 


\section{AUTEUR}

MARIE-AGNÈS SCHMITT

mas.traductions@orange.fr 